\title{
Student-Generated Stop-Motion Animation in Science Classes: a Systematic Literature Review
}

\author{
Mohammadreza Farrokhnia ${ }^{1}$ (D) Ralph F. G. Meulenbroeks ${ }^{2} \cdot$ Wouter R. van Joolingen $^{2}$ \\ Published online: 10 September 2020 \\ (C) The Author(s) 2020
}

\begin{abstract}
In recent years, student-generated stop-motion animations (SMAs) have been employed to support sharing, constructing, and representing knowledge in different science domains and across age groups from pre-school to university students. The purpose of this review is to give an overview of research in this field and to synthesize the findings. For this review, 42 publications on student-generated SMA dating from 2005 to 2019 were studied. The publications were systematically categorized on learning outcomes, learning processes, learning environment, and student prerequisites. Most studies were of a qualitative nature, and a significant portion (24 out of 42) pertained to student teachers. The findings show that SMA can promote deep learning if appropriate scaffolding is provided, for example, in terms of presenting general strategies, asking questions, and using expert representations. Also, the science concept that is to be presented as a SMA should be self-contained, dynamic in nature, and not too difficult to represent. Comparative quantitative studies are needed in order to judge the effectiveness of SMA in terms of both cognitive and non-cognitive learning outcomes.
\end{abstract}

Keywords Modeling-based learning $\cdot$ Student-generated animation $\cdot$ Stop-motion animation $\cdot$ Slowmation $\cdot$ Science learning

\section{Introduction}

Visual representations have been reported to contribute to the development of students' learning of science (Evagorou et al. 2015; Heijnes et al. 2018). Moreover, the results of previous studies confirm that learning gains are greater when students generate their own representations in general, as opposed to working with expert-generated representations (Kozma and Russell 2005; Wu and Puntambekar 2012). Student-

This research was done at the time when the first author was a visiting researcher at The Freudenthal Institute for Science and Mathematics Education, Utrecht University, The Netherlands

Mohammadreza Farrokhnia

Mohammadreza.Farrokhnia@wur.nl

Ralph F. G. Meulenbroeks

r.f.g.meulenbroeks@uu.nl

Wouter R. van Joolingen

w.r.vanjoolingen@uu.nl

1 Faculty of Social Science, Education and Learning Science Group, Wageningen University and Research,

Wageningen, The Netherlands

2 Freudenthal Institute for Science and Mathematics Education, Utrecht University, Utrecht, The Netherlands generated representations have been used to evaluate students' understanding of scientific concepts (Hubber et al. 2010; Zhang and Linn 2011), to make connections with prior knowledge (Akaygun and Jones 2013), to identify conflicts among their ideas (Chi 2009), and to provide feedback about students' understanding (Stieff et al. 2005). They can help students to become more than just consumers of knowledge (Danish and Enyedy 2007), but active learners (DiSessa and Sherin 2000; Yaseen and Aubusson 2018). These advantages have been shown for a variety of student-generated representations, such as diagrams (Davidowitz et al. 2010; Gobert and Clement 1999), sketches (Quillin and Thomas 2015), animations (Nordin and Osman 2018), and simulations (Olde and de Jong 2004).

Focusing on student-generated animations, Hoban (2009) distinguishes three main forms: hand-drawn, stop-motion, and computer-based animation. Hand-drawn animations are based on students' own analog drawings. Stop-motion animation (SMA) involves taking digital still photographs of objects or pictures after they have been moved manually to simulate movement, and computer-based animation involves employing computer-generated images as the basis for the animation. Hoban and Nielsen (2013) argue that SMAs have two key advantages over the other kind of animations. Firstly, their inherent simplicity means that students can easily and quickly learn the technique. Secondly, it only requires 
ubiquitous technology such as a digital still camera and a computer in order to generate the illusion of motion. Moreover, since a SMA is created frame by frame and can be played in slow motion using a computer (Macdonald and Hoban 2009), students reported having enough time to grasp the underlying concepts (Hoban 2007).

From 2005 onwards, a sizable body of research has focused on the use of these student-generated SMAs in educational contexts (Brown et al. 2013; Ekici and Ekici 2014; Hoban and Nielsen 2014; Mills et al. 2018b; Wilkerson et al. 2018). However, no overview of this research is currently available. Also, the results on the effectiveness of the application of SMAs in education are inconsistent. This inconsistency can be attributed to a variety of causes, ranging from inadequate pedagogical understanding on how to integrate digital technology (Vratulis et al. 2011), lack of students' digital literacies (Paige et al. 2016), lack of students' argumentation and negotiation skills (Kidman and Hoban 2009), lack of students' representational literacies and higher-order thinking skills (Brown et al. 2013), and to the problem of cognitive load due to the use of SMAs for representing inappropriate science concepts (Kidman and Hoban 2009).

Therefore, the main objective of the current review is to systematically identify, critically analyze, and discuss scientific research on student-generated SMAs to enable educators to make the best use of SMAs in science classes. Besides, this review study also aims to highlight the research gaps, providing directions for future research in the field. In line with Noroozi et al. (2012), we employ learning outcomes, learning processes, learning environment, and student prerequisites (inspired by Biggs's (2003) 3P Model) as main categorical descriptions in this review study. This structure allows us to categorize available research findings at any educational level into sections that are relevant to both educators and science education researchers, highlighting both the main findings and main avenues for further research of the four components.

Therefore, based on the four components mentioned above, the following research questions are formulated to be answered in this study:

- RQ1. What research findings are available regarding the relationship between student-generated SMA and learning outcomes in science classes?

- RQ2. What research findings are available regarding learning processes involving student-generated SMAs?

- RQ3. What research findings are available on the learning environment prerequisites in relation to student-generated SMAs?

- RQ4. What research findings are available on the student prerequisites in relation to student-generated SMAs?

\section{Method}

This work follows the systematic literature review protocol by Brereton et al. (2007). For this review, we adapted a narrative analysis (Van Dinther et al. 2011) approach identifying current trends and also practical implications of studentgenerated SMA as a learning approach in science classes from a holistic point of view, contributed by the adopted framework as our theoretical basis. The result of this narrative analysis will be more qualitative than quantitative, providing in-depth information about the topic under study (Dochy et al. 2003).

\section{Literature Search}

Literature search was conducted on the following databases: Scopus, Web of Science (WoS), ERIC, Science Direct, and Google Scholar. We have limited the search to English publications with an available full-text version. The time span for the search was limited from 2005 through 2019. The last search was performed on August 10, 2019.

For selecting the most relevant keywords to the research scope, in a first step, we identified synonyms or related terms concerning SMA, and we found the terms Stop-action animation, Slow-motion animation, Slowmation, and flipbook-like animation. In the second step, we combined the related terms with the Boolean operators OR and the overlapping concept areas with AND to arrive at the following search string: Learn* OR understand* AND physics OR chemistry OR biology OR Geology OR science AND Slowmation OR Slow-motion animation OR Stop-motion animation OR Stop-action animation OR Flipbook-like animation. We composed the search string in each of the five databases manually based on the search functionality offered by that database.

\section{Criteria for Inclusion}

The literature search and publication selection process is shown in Fig. 1. The initial search resulted in 29 papers in Scopus, 21 papers in WoS, 4 papers in ERIC, 51 papers in ScienceDirect, and 33 papers in Google scholar. Among the findings, 54 papers appeared to be duplicated. Then, five inclusion criteria were employed for screening the abstracts and collecting relevant studies:

1. The study investigated the stop-motion technique for generating an animation.

2. The SMA had to be generated by the students - at any level (e.g., from pre-elementary to tertiary education).

3. The study had to report quantitative and/or qualitative data.

4. The study had to be performed in science classes (i.e., physics, biology, chemistry, and geology). 
Fig. 1 Selection process

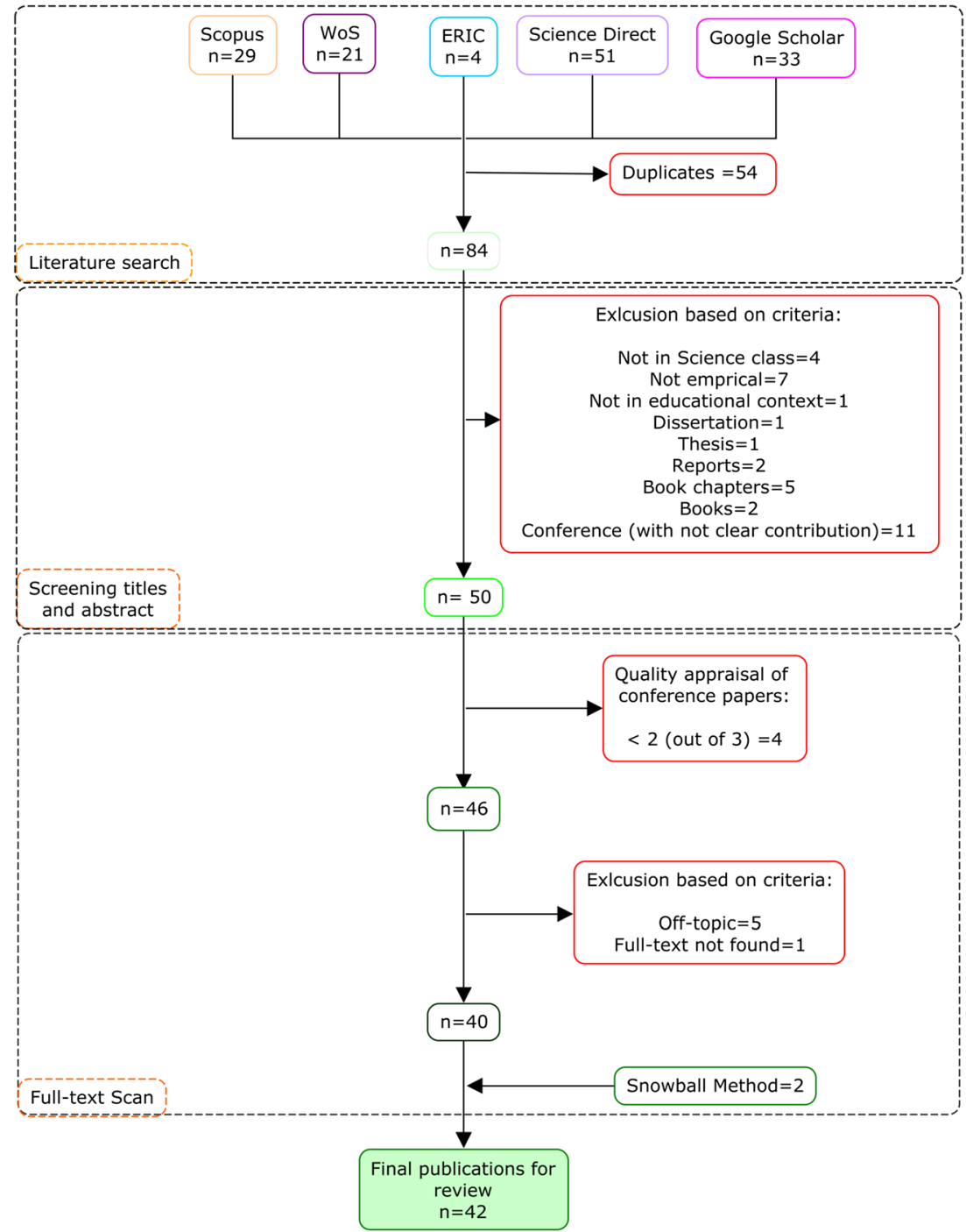

5. The study had to address educational purposes, e.g., learning outcomes, learning processes, design procedures of SMA in an educational context, and/or SMA as a teaching approach.

After reading the abstracts, 50 studies (37 peer-reviewed and 13 conference papers) remained for a full reading. Studies that did not meet one or more of the above criteria were excluded for analysis.

\section{Identification of Relevant Publications}

In the next step, full texts were analyzed using the abovementioned inclusion criteria. Also, to ensure the quality of conference papers, we adopted criteria by Theelen et al. (2019) (p.19) for quality appraisal of qualitative and quantitative empirical studies. Among the 13 conference papers which had a clear contribution, four papers were excluded for further review after quality appraisal (mean score below 2). Moreover, six other papers were excluded since they turned out to be off-topic or were not available full text. Also, snowballing the references of included articles yielded another two peer-reviewed studies. After reading the abstracts and full texts, both of them were included in the review.

Eventually, 42 publications were retained for the review, all pertaining to quantitative and/or qualitative empirical data on using the stop-motion technique for developing an animation in science classes. A complete list of reviewed publications is provided in Appendix 1 and is indicated by asterisks in the Reference section.

\section{The Quantitative Description of Scientific Research into Student-Generated SMAs}

Figure 2 shows the number of papers published each year. The observed slight increase in recent years can be the result of the 
Fig. 2 Yearwise distribution of selected papers

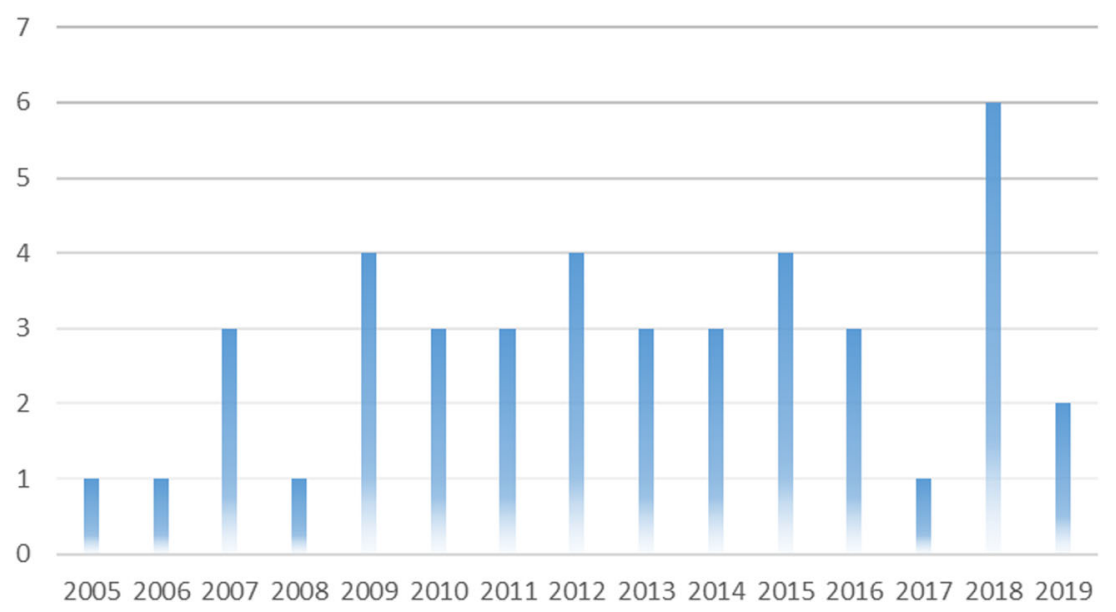

growing tendency toward technology-based learning environments in science classes (see Oliveira et al. 2019).

Twenty-eight of empirical studies (out of 42) used qualitative methods (e.g., surveys, interviews, and observations) to analyze student-generated SMA processes and outcomes; only six exclusively used quantitative methods. The remaining eight used both qualitative and quantitative methods (i.e., mixed method). Student-generated SMAs have been reported to be used in different science classes such as biology (14 publications), multi-domain (different science classes) (11), physics (9), chemistry (4), geology (2), and general science (2). The educational context of the empirical studies varied among undergraduate student teachers (24 publications), students in secondary (6), elementary (5), middle (4) schools, and multi-level (e.g., elementary, middle, and secondary) (2) and pre-elementary (1) students. Table 1 summarizes these quantitative results.

Table 1 Quantitative data description of the reviewed papers

\begin{tabular}{llrl}
\hline Variables & Items & $\begin{array}{l}\text { Number of } \\
\text { publications }\end{array}$ & Percentage \\
\hline Type of analysis & Qualitative & 28 & 66.7 \\
& Quantitative & 6 & 14.3 \\
& Mixed & 8 & 19.0 \\
Class (subject) & Biology & 14 & 33.3 \\
& Multi-domain & 11 & 26.2 \\
& Physics & 9 & 21.4 \\
& Chemistry & 4 & 9.5 \\
& Geology & 2 & 4.8 \\
& Science (general) & 2 & 4.8 \\
Educational level & Student teachers & 24 & 57.2 \\
& Secondary school & 6 & 14.3 \\
& Elementary school & 5 & 11.9 \\
& Middle school & 4 & 9.5 \\
& Multi-level & 2 & 4.7 \\
& Pre-elementary & 1 & 2.4 \\
\hline
\end{tabular}

\section{Results}

Following the structure of our research questions, we extracted the influential and constitutional factors of employing student-generated SMA as a teaching and learning approach in science classes from the reviewed publications and categorized them into four inter-related components: learning outcomes, learning process, learning environment, and student prerequisites.

\section{What Research Findings Are Available Regarding the Relationship Between Student-Generated SMA and Learning Outcomes in Science Classes?}

In most studies, cognitive and non-cognitive learning outcomes were among the most frequently reported outcomes of using student-generated SMA in science classes. While cognitive learning outcomes are those knowledge-related attributes usually measured by students' overall GPA (Walker 2008) or exam scores (Shi et al. 2020), non-cognitive outcomes are generally viewed as attitudes, behaviors, and values (Levin 2012) that can contribute to students' educational performances (Wanzer et al. 2019).

Concerning the cognitive outcomes, many favorable results on domain-specific knowledge are reported in the reviewed papers. However, some studies showed inconclusive or neutral results. Also, an increase in motivation and engagement has been reported as non-cognitive outcomes of student-generated SMAs. Moreover, domain-general skills such as reasoning, collaboration, and digital literacy skills are generally reported to be positively influenced by the application of SMA. For the specific target group of student teachers, a remarkable outcome is that their knowledge of instructional strategies concerning the use of SMAs in science classes did not seem to develop.

Cognitive Learning Outcomes Several papers reported significant improvement in students' domain-specific knowledge 
(Ekici et al. 2014; Hoban et al. 2009a; Jablonski et al. 2015; Macdonald and Hoban 2009; Wilkerson et al. 2015; Wishart 2017; Yaseen and Aubusson 2018). Also, according to the reviewed papers, student-generated SMAs facilitate conceptual understanding by revising mis- or alternative conceptions and improving students' mental models (Akaygun 2016; Brown et al. 2013; Church et al. 2007; Fleer and Hoban 2012; Hoban and Nielsen 2013, 2014; Keast et al. 2010; Kidman et al. 2012; Loughran et al. 2012; Mills et al. 2018a; Nielsen and Hoban 2015; Peter et al. 2011).

Neutral or conflicting results have also been reported. Chang et al. (2010) found that students' understanding of science concepts was better for students who only viewed the animation than the students who designed and developed their animation. Only when integrating peer-evaluation and designing, a significant improvement of students' learning was found. Peter et al. (2011) pointed out that there was no significant difference between students' conceptual understanding among SMA and paper sketch groups. Also, in Ekici et al.' s (2014) study, despite higher achievement scores for SMA generated groups immediately after the intervention, no statistical difference in retention test scores was found between control and experimental groups.

Non-cognitive Learning Outcomes The majority of studies that address non-cognitive learning outcomes report an improvement in motivation, engagement, and interest through the use of SMAs. The autonomy support that is implicit in allowing students to develop their own animations increases autonomous types of motivation and, eventually, engagement (Bogiages and Hitt 2008; Brown et al. 2013; Hoban 2005, 2007; Hoban and Nielsen 2010; Jablonski et al. 2015; Mills et al. 2018b; Peter et al. 2011; Wilkerson et al. 2015). Mills et al. (2018b) study reports differentiated findings in this respect. Despite an improvement in students' individual interest in learning geology, their maintained situational interest value, i.e., the belief that the content itself is meaningful to one's life beyond the classroom (Linnenbrink-Garcia et al. 2010), did not improve. Also, Church et al. (2007) claimed that generating a SMA concerning an event of interest in the student's life (i.e., connecting more closely with their personal lives) appears to improve their motivation and engagement better.

Domain-General Knowledge and Skills Wilkerson et al. (2018) reported that students' mechanistic reasoning skills could be elicited and improved by creating mechanistic models with a combination of multiple representations, i.e., drawing, SMA, and simulation. Berg et al.'s (2019) study illustrated that the SMA task enabled students to better engage in reasoning concerning both the macro (i.e., observable) and the submicro-level (i.e., a level that cannot be observed) models, and how they relate to each other. Nordin and Osman (2018) found that student-generated SMA can be effective in fostering collaborative problem-solving skills in terms of establishing and maintaining shared understanding and group organization toward finding the appropriate action to solve a physics problem in secondary education. The results of some studies also revealed that the SMA task contributed to the development of twenty-first-century skills such as creativity, communication, and cooperation skills, information literacy, research skills, technology, and media literacy skills (Atalay and Belet Boyaci 2019; Karakoyun and Yapic1 2018). Skills in using technology, such as taking photos with digital cameras, were also reported as an outcome of intentionally teaching using SMA in early childhood science classes (Fleer and Hoban 2012).

Researchers also noticed that their student teachers were able to further their abilities in many other areas aside from 'just science', including information and technology skills, creative writing, group work, and research (Keast et al. 2010; Kidman et al. 2012). Having student teachers create a narrated SMA to explain a science concept in Hoban and Nielsen's (2014) study provided a context for generating discussions, exchange, and clarification of ideas, which finally contributed to scientific reasoning skills.

Knowledge of Instructional Strategies Although research confirmed the possibility and the benefits of generating SMA as a teaching approach in science classes (Ekici and Ekici 2014; Fleer and Hoban 2012; Hoban et al. 2007; Keast et al. 2010; Loughran et al. 2012; Nielsen and Hoban 2015; Paige et al. 2016), Vratulis et al. (2011) stated that student teachers did not encourage their pupils to design and make SMA projects in practice-despite the student-centered approach advocated during the program. Therefore, knowledge and beliefs about instructional strategies for teaching science as one of the main elements of Magnusson et al.'s (1999) pedagogical content knowledge model, did not improve in this study. Vratulis et al. (2011) concluded that introducing student teachers to alternate instructional strategies employing digital technology as learners in a teacher education program in itself is not enough for them to deploy these technologies in their schools.

\section{What Research Findings Are Available Regarding Learning Processes Involving Student-Generated SMAs?}

The learning process involving SMA turns out to be cyclical rather than linear. Both surface and deep learning are encountered in the studies on SMA, depending on the amount of scaffolding provided. The learning activities such as class discourse about the generated SMAs and peer-evaluation bring to the fore students' sometimes conflicting ideas and thus stimulates deeper learning. Moreover, putting narration on the generated SMA can provoke a better understanding of the subject matter. Several scaffolding techniques, such as 
presenting general strategies, asking questions, and the use of expert representations, are reported.

Learning Process In order to improve learning in any learning environment, it is important to understand students' learning processes (Beyaztaș and Senemoğlu 2015). The more instructors understand this process, the better their chance of meeting the diverse learning needs and scaffolding their students' learning (Felder and Brent 2005). In this line, Kidman (2015) distinguishes first- and second-order learning in the context of the process of generating SMAs. First-order learning refers to considering only observable characteristics of the phenomena, with very little analysis of the visual representation to be made. Second-order learning (or deep learning) emerges once the learner engages in the science content behind the phenomenon. Here, the learner mentally engages with prior knowledge, the new information provided in published sources, and the information interpretation provided by group participants. The learner makes meaning of all this information and then re-represents the new findings in a SMA.

Hoban et al. (2009b) observe that the learning pathway in the SMA learning approach is cyclical, iterative, and dynamic rather than linear. This recursive checking of information was clearly manifested in Hoban et al.'s (2011) study when students referred back to the support material and discussed it with their peers. Also, according to Kidman et al.'s (2012) observations, in a collaborative setting, groups can choose to superficially accept one representation of the chunks (i.e., surface learning) or through discussion and planning agree by consensus on the key "chunks" that need to go in their SMA (i.e., deep learning). According to scholars, this iterative process is responsible for revealing and revisiting students' misconceptions (Hoban et al. 2009b; Hoban and Nielsen 2013) and encouraging their conceptual learning (Hoban et al. 2011).

Learning Activities According to Wilkerson et al. (2015), intentionally letting students generate and evaluate knowledge, e.g., asking them to construct a model and share their product individually, will help them to both realize the wealth of knowledge they already have about the subject and evaluate that knowledge. Moreover, scholars reported that asking students to share their final products can also bring their conflicting ideas and uncertainties about the science concept to the fore (Mills et al. 2018a), leading to a substantive discourse in the classroom (Brown et al. 2013). This discourse, especially in the form of peer-evaluation, can effectively improve the accuracy of the representations (Hoban and Nielsen 2014) and contribute to students' conceptual learning (Chang et al. 2010; Mills et al. 2018a) and student teachers' better mastery of subject matter (Hoban and Nielsen 2013). In this regard, Kamp and Deaton (2013) reported that providing a rubric for students' peer-evaluation could support the evaluation process of final student-generated SMAs. Also, Hoban and Nielsen (2013) claimed that clear explanation as a narration in the final representation provoked the student teachers' better realization of subject matter.

Scaffolding Techniques In their study with 28 elementary school students, Wilkerson et al. (2018) found that groups struggling to construct a model progressed when they received guidance about general modeling strategies (i.e., rules and constraints for making a model), but not when they received guidance about model content. They claim that in terms of complex systems reasoning, students benefit from explicit support in considering the elements, behavior, and interactions in a system both before and during the exploration and construction of models. Their findings also highlight that an iterative modeling activity across multiple representations (drawing, SMA, and simulation) can facilitate and deepen student learning and engagement.

According to Nielsen and Hoban's (2015) study, expert's representations can scaffold students' understanding while students discuss their own representations. In the same line, Yaseen and Aubusson (2018) claim that teachers can ask students to identify, discuss, explain, and map the similarities and differences between student- and expert- generated animations. They reported that with this sort of mediation, conceptual learning was improved more than if the students had only viewed the experts' animations.

Also, asking questions by the teacher is highlighted in some papers as a way to scaffold students "learning toward the science part of the animation during the developing process of a SMA" (Mills et al. 2018a; Wilkerson et al. 2015; Yaseen and Aubusson 2018). In Yaseen and Aubusson (2018)'s study, students focused on the technical quality of animation, but the teacher took the discussion beyond this, by asking students to consider the scientific propositions implicit in the animations. These guiding questions helped the students to both understand and explain the exact science concepts related to the subject of their SMA. Also, they claim that teachers can enhance students' critical thinking by asking why their SMA might be inadequate and how it could be improved and by showing them other ways of looking at a specific concept. Similarly, Mills et al. (2018a) reported that teachers' questions to encourage thinking and provoke scientific explanations were crucial in revising students' conflicting ideas and developing conceptual understanding.

\section{What Research Findings Are Available on the Learning Environment Prerequisites in Relation to Student-Generated SMAs?}

The findings suggest that the science concept needed to be presented as a SMA by students should be self-contained, dynamic in nature, and not too difficult to represent. As for 
software and hardware, most studies employ generic software, and this is sometimes claimed to be an essential prerequisite. There are, however, several studies based on software developed specifically for the creation of SMAs. A collaborative setting is chosen in almost all studies since discourse during the process of constructing an SMA is considered to be of prime importance for more in-depth learning.

Characteristics of the Science Concept Keast et al. (2010) found that the SMA approach was shown to be most effective when it used to present a science concept which is small, selfcontained, and easy to chunk and represent. Peter et al. (2011) reported that student-generated SMA improves learning, especially for content that involves dynamic events, e.g., moon phase, cellular division, or smell diffusion. In terms of cognitive load, Kidman and Hoban (2009) claimed that when a topic requires a considerable representation effort (such as the fiddly detail in the representation of chromosome mapping), cognitive load focuses on the representation, rather than scientific processes.

Software and Hardware Hoban et al. (2011) claimed that a key feature of generating a SMA is that it does not involve the use of any specific software. In most of the studies, learners used generic software such as Apple's QuickTime Pro (Hoban 2005; Hoban and Ferry 2006; Vratulis et al. 2011), Windows Movie Maker (Jablonski et al. 2015; Nordin and Osman 2018; Wishart 2016), SAM animation (Church et al. 2007; Hoban et al. 2009a; Hoban and Nielsen 2013; Wilkerson et al. 2015) and mobile apps like MyCreate (Mills et al. 2018b), iMotionHD (Wishart 2017), and iStopMotion (Berg et al. 2019; Kamp and Deaton 2013).

In some studies, however, domain-specific software was used to develop student-generated SMAs. For example, Chang et al. (2010) used "Chemation" for making a molecular SMA in Chemistry. Akaygun (2016) used "ChemSense" which is specifically designed to generate drawings and animations for chemistry concepts through a stop-motion technique. Yaseen and Aubusson (2018) used K-Sketch for generating SMAs about different states of matter by students. Akaygun (2016) also suggested that participants in K-Sketch produced their animations faster and had a significantly lower cognitive load than common animation software, such as ChemSense, with which it was compared. Also, according to his findings, K-Sketch provides the most freedom for representing dynamics, and ChemSense provides more options for representing structural features. SiMSAM (Simulation, Measurement, and Stop-Action Moviemaking) allows students to create SMAs by using an external camera to capture successive photos of drawings or craft materials and was used in different studies by Wilkerson et al. $(2015,2018)$. This software was designed specifically to support learners in "discovering" aspects of kinetic molecular theory.
Setting: Collaborative/Individual Most of the empirical research in the domain of student-generated SMAs have been performed in a collaborative setting (Brown et al. 2013; Jablonski et al. 2015; Mills et al. 2018a; Vratulis et al. 2011; Wilkerson et al. 2015, 2018; Wishart 2016, 2017; Yaseen and Aubusson 2018). Many researchers argued that generating discussion is the main benefit of student-generated SMAs in collaborative settings. Brown et al. (2013) claim that the collaborative creation of a SMA facilitates rich opportunities for students to use discourse as a representational form to generate and mediate between other representational forms. Their findings are in line with Hoban and Nielsen's (2014) study, which suggests having student teachers create a narrated animation in order to explain science, the narrative sparking subsequent discussion. Loughran et al. (2012) found that collaborating with peers in developing SMAs helped student teachers recognize and respond to a range of pre- or alternative conceptions that they held, not only in terms of pre-conceptions' nature but also in terms of their origin and possible address in the classroom.

According to Wishart (2016, 2017), group discussions were found to be key to student science learning through the co-construction of meaning. In the same line, Kidman (2015) asserted that SMA, when used in a collaborative inquiry-based learning context, is a technique in which "the new 'meaningmaking' of the designers facilitates the new 'meaning-making' of others." Paige et al.'s (2016) study with science student teachers showed that working in a collaborative setting was preferred to an individual setting by the students.

\section{What Research Findings Are Available on the Student Prerequisites in Relation to Student-Generated SMAs?}

SMA can be used at all age levels from pre-school to university, an important subset of studies ( 24 out of 42 ) pertaining to student teachers. There are conflicting results on the importance of prior knowledge for the construction of a SMA. Digital literacy, however, does appear to be an important factor.

Age The main trend is that SMA can be applied to almost all age levels, from early childhood to university classrooms (Hoban and Nielsen 2014). Studies include 4-year olds learning science concepts (Fleer and Hoban 2012), elementary classes co-constructing spinning in space through collaborative generating of a SMA (Brown et al. 2013), and smell diffusion by grade 6 students through multimodal representation, including SMA (Wilkerson et al. 2015).

On the middle school level, more studies with SMA have been performed (e.g., Jablonski et al. 2015; Mills et al. 2018a; Mills et al. 2018b). The same holds for secondary school classrooms (e.g., Church et al. 2007; Kamp and Deaton 2013). In the context of university teacher education 
programs, there have been many studies ( 24 out of 42 ) on how creating a SMA influenced student teachers in learning various science concepts (Berg et al. 2019; Hoban et al. 2009a; Hoban and Nielsen 2012, 2013), pedagogical intent (Hoban et al. 2007; Hoban and Ferry 2006; Keast et al. 2010; Nielsen and Hoban 2015), and technological pedagogical content knowledge (Paige et al. 2016). Finally, Wishart (2016), in a multi-level study (primary, middle, and secondary school), found that students of different ages can benefit from generating SMA in science classes. She found that the younger students (aged 8-9) most often enjoyed making, whereas the older ones (aged 15-16) most enjoyed seeing their finished results.

Prior Knowledge Kidman et al. (2012) compared learning processes in student-generated SMAs with Peirce's (1955) model of semiotic systems and claimed that students 'prior knowledge serves as a "referent" in this system, and it is important for starting the cumulative semiotic progression responsible for learning through generating SMA. As learners revisit their prior knowledge through different semiotic systems during design and development, building from one representation to the next promotes learning (Nielsen and Hoban 2015). However, Hoban and Nielsen (2013) found that the process of creating a SMA was effective even if students (pre-school children) did not have any prior knowledge about the domain. This finding is in line with Church et al. (2007) and Mills et al. (2018a), who found that the SMA task induced higher cognitive activity and led students to critically examine their own mental models even in the absence of prior instruction.

Digital Literacies Paige et al. (2016) found that learners who were novices in digital literacies had difficulties accessing basic digital technology and equipment, impeding their construction of a SMA. This finding supports the general importance of improving ICT skills in a cross-curricular fashion. Brown et al. (2013) claim that explicit teaching of representational literacies, i.e., to effectively communicate ideas using multimedia (Flood et al. 2004), could be beneficial in this respect.

\section{Discussion and Conclusions}

Overall, the reviewed papers agree that engaging in designing and developing a SMA can facilitate the acquisition of different domain-specific/general knowledge and skills as well as non-cognitive learning outcomes in different scientific contexts. However, studies report varying and sometimes conflicting results on students' conceptual learning (Chang et al. 2010; Peter et al. 2011), retention (Ekici et al. 2014), interest (Mills et al. 2018b), and student teachers' knowledge of instructional strategies development (e.g., Vratulis et al. 2011).
Regarding the latter, a striking finding was that student teachers did not start to use SMA in their own classes, indicating that their knowledge of instructional strategies had not matured.

The central focus of reviewed papers is on learning processes and activities in student-generated SMAs, pertaining to surface and deep learning processes and scaffolding techniques toward specific learning activities. Peer-evaluation and adding narration stand out as activities that can improve the learning outcomes of student-generated SMAs. Deep learning during the generation of a SMA does not happen automatically (Kidman 2015; Kidman et al. 2012), and it needs scaffolding techniques in the form of:

(1) explicit support in considering elements, behaviors, and both before and during the construction of the SMAs (Wilkerson et al. 2018);

(2) discourse on similarities and differences between student- and expert-generated animations (Nielsen and Hoban 2015; Yaseen and Aubusson 2018);

(3) teachers' questions highlighting the science aspects of the animation, provoking students' critical thinking (Mills et al. 2018a; Wilkerson et al. 2018; Yaseen and Aubusson 2018);

(4) teaching the modes of discourse and the skills for classroom discussion and collaborative learning (Brown et al. 2013); and

(5) providing rubrics for peer-evaluation (Kamp and Deaton 2013).

Some of the findings are in line with other studies in the field of modeling-based learning. For example, in comparing student- and expert- generated animations, it was found that a discussion on the (mis)match between animations and target phenomenon may be more valuable to students' learning than the development of a more accurate animation per se (Aubusson et al. 2009). Yaseen and Aubusson (2018) argued that the errors and imperfections in student-generated SMAs create a locus for learning. Their findings also support the idea that relatively weak student-generated animations can be better stimuli for students' learning than expert animations.

There is a small but growing body of research focusing on learning environment prerequisites for using studentgenerated SMAs, in terms of resources and settings. The consensus among researchers is that the science concept which is used for developing a SMA should be small, self-contained, and easy to chunk and represent dynamic events, preferably related to learners' daily life. A plausible explanation is that a highly complex topic adversely influences the learning task by requiring a great effort in the actual representation. This can take attention away from the scientific process or concept.

In most of the studies, learners designed and developed SMAs in a collaborative setting. Findings reveal that the 
construction process encourages a practice of collaborative learning and requires that students negotiate what content to include and how to represent their ideas in multiple modalities. Brown et al. (2013) demonstrate that the use of SMA techniques prompted students to work cooperatively and develop their cooperation skills.

Although many researchers argued that having prior domain knowledge is crucial for starting the cumulative semiotic progression in generating a SMA, Macdonald and Hoban (2009) found that prior knowledge is not predictive for the results of a knowledge post-test. This result can be interpreted by referring to the design procedure of a SMA, that in the first step, students are needed to enrich their content knowledge about a given science concept. Thus, this initial step helps them to acquire needed knowledge for building the SMA.

\section{Implications for Research and Practice}

In our review, the qualitative studies outnumber the quantitative ones, which indicates a further need for quantitative research in the field. As qualitative research on pedagogical effects of student-generated SMAs in science classes dominates the field so far, several researchers recommend (quasi-) experimental designs to generate data to compare the learning outcomes with those of other forms of instruction, such as direct instruction or constructivist approaches (Hoban et al. 2011; Hoban and Nielsen 2013, 2014).

While there has been much mention of both personality and cognitive factors relating to learning with external representations (see ChanLin 2001; Klein 2003), no research has been found to assess or control for these factors in student-generated SMA. For example, many researchers argued that spatial ability is crucial for any modeling activity, especially when students are engaged with dynamic and static visualization (Höffler 2010; Sudatha et al. 2018). Spatial ability is defined as the ability of "thinking about the shapes and arrangements of objects in space and about spatial processes, such as the deformation of objects, and the movement of objects and other entities through space" (Marunic and Glazar 2014). Mayer (1994) found that students with lower spatial ability have difficulties processing and profiting from the animations, and students with higher spatial ability profit from such animations. Although Nielsen and Hoban (2015) referred to spatial ability as a critical factor for generating SMA, none of the studies in this review considered and controlled for this ability. Therefore, it is recommended to conduct quantitative studies controlling for spatial ability as well as other personality and cognitive factors.
Some studies suggest working with multiple ages, genders, and cultural influences to examine social factors in using SMAs in the classroom (Church et al. 2007), or to repeat the study with a range of learners such as student teachers and different levels of students in general (Hoban et al. 2011). Also, with regard to the collaborative settings, future research has to take into account crucial factors such as group composition (Wishart 2017), demographic population, and group size (Brown et al. 2013).

Most of the studies conducted so far have focused mainly on pre and post data collection and not on data collection during the actual development process. In this regard, Yore and Treagust (2006) state that there have been few studies to investigate the "enhanced cognition that occurs during the transformation from one representation to another representation or one mode to another" (p. 208). Therefore, there is a need for further research on learning outcomes, and on the nature of the learning process, how that learning develops both in and between the different stages of creating a SMA. This will improve the understanding of how each representation or mode influences learning, especially in relation to the proposed educational affordance (Hoban et al. 2009a; Hoban and Nielsen 2010, 2012; Wishart 2016).

Although some research has been done on teacher practices and instructional strategies of successful implementation of SMA, there is a need for more research focusing on the role of the teacher in supporting student learning with this modeling technique (Chang et al. 2010).

Last but not least, teachers and researchers should pay close attention to the different learning pathways (i.e., deep vs. superficial learning). Since it is quite common and easy for the students to take the surface learning pathway, teachers should employ different scaffolding techniques such as guidance about general modeling strategies, showing expert-generated animations, asking questions, and providing a rubric for peer-evaluation in order to elicit deeper learning.

Data Availability Statement Data sharing is not applicable to this article, as no new data were created or analyzed in this study. However, the exported EndNote files from each database are available from the corresponding author upon reasonable request.

\section{Compliance with Ethical Standards}

Conflict of Interest The authors declare that they have no conflict of interest.

Ethical Approval This article does not contain any studies with human participants or animals performed by any of the authors.

Informed Consent No human participants were involved in the scope of this study. 


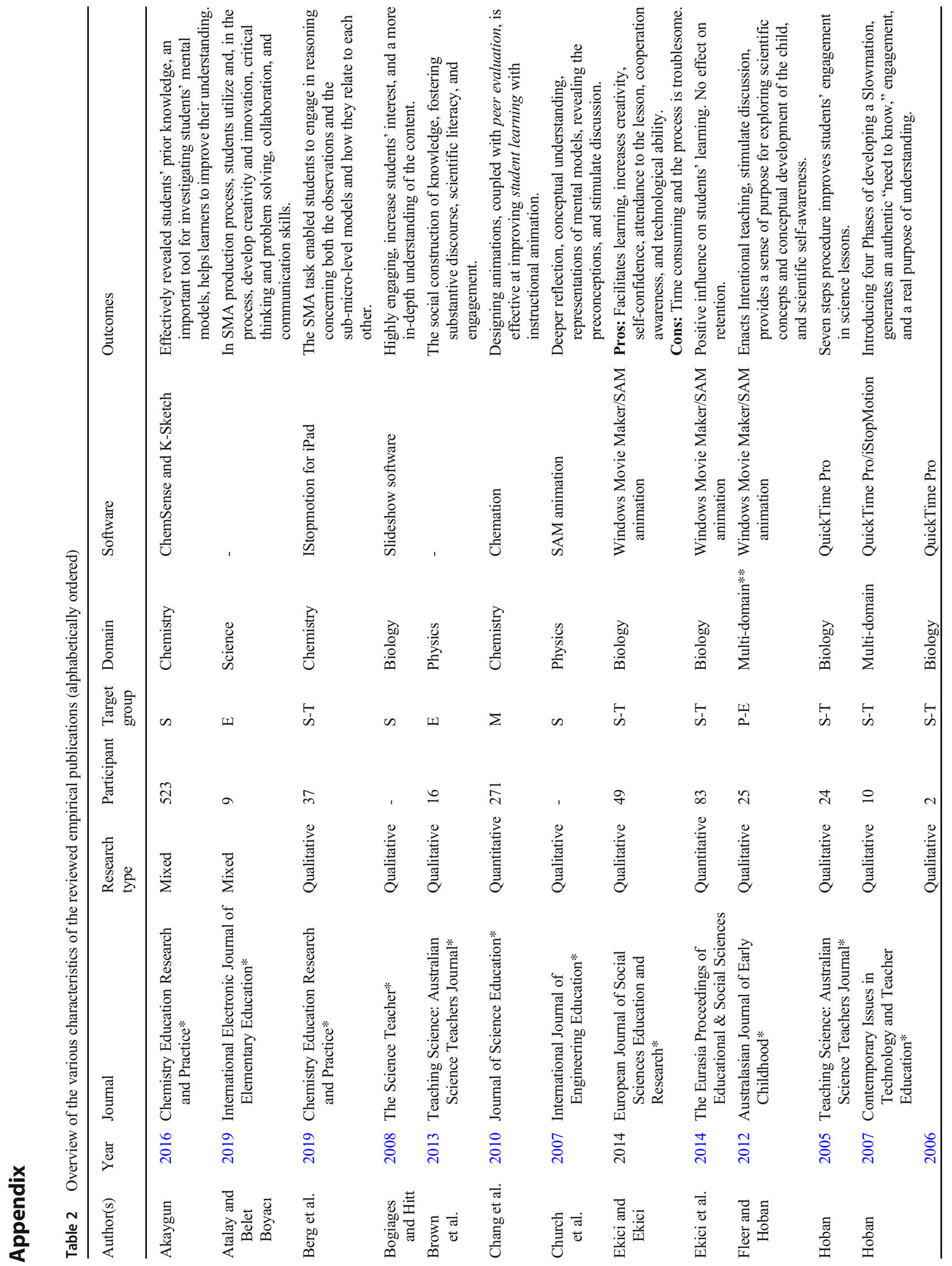




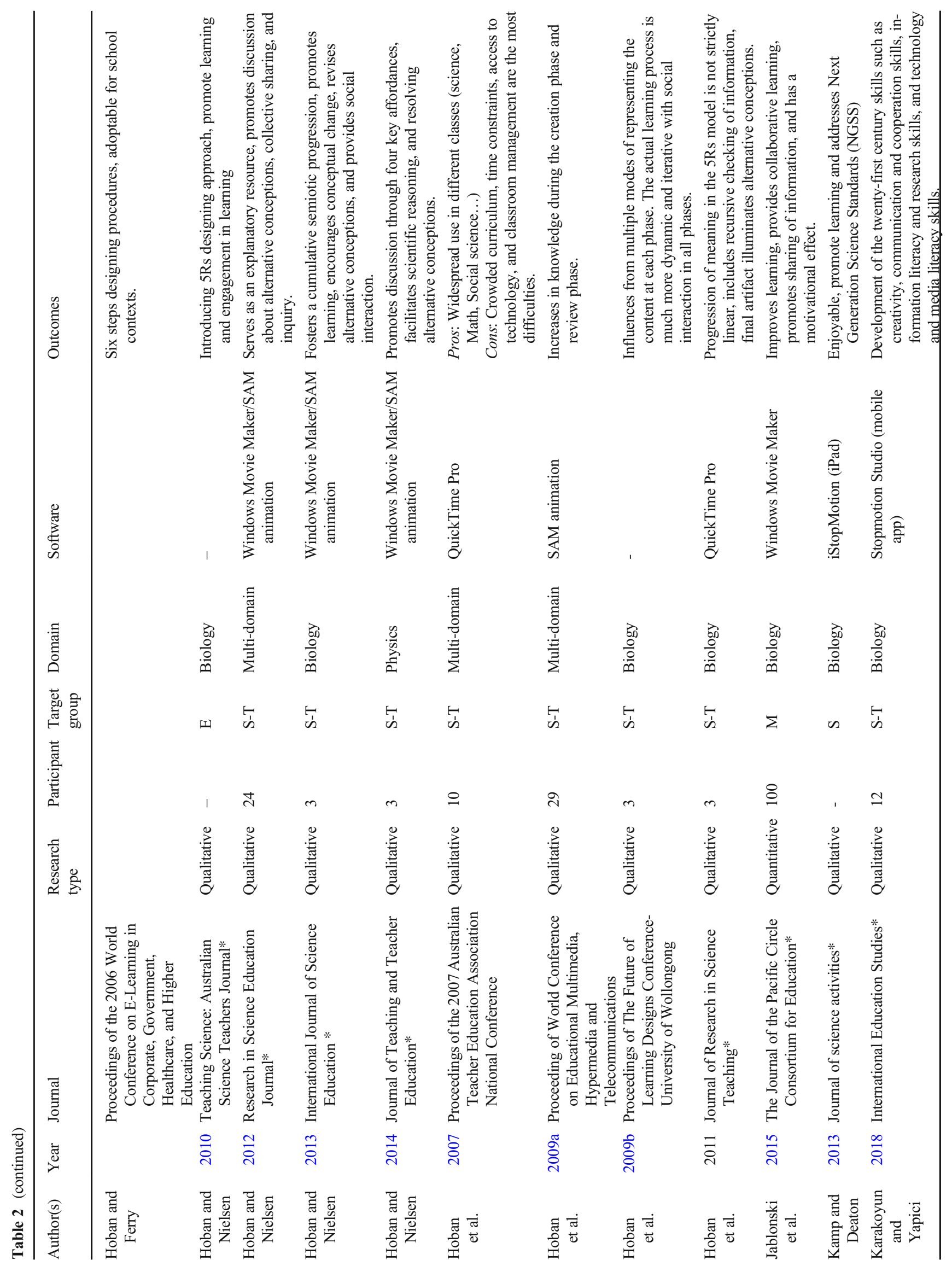




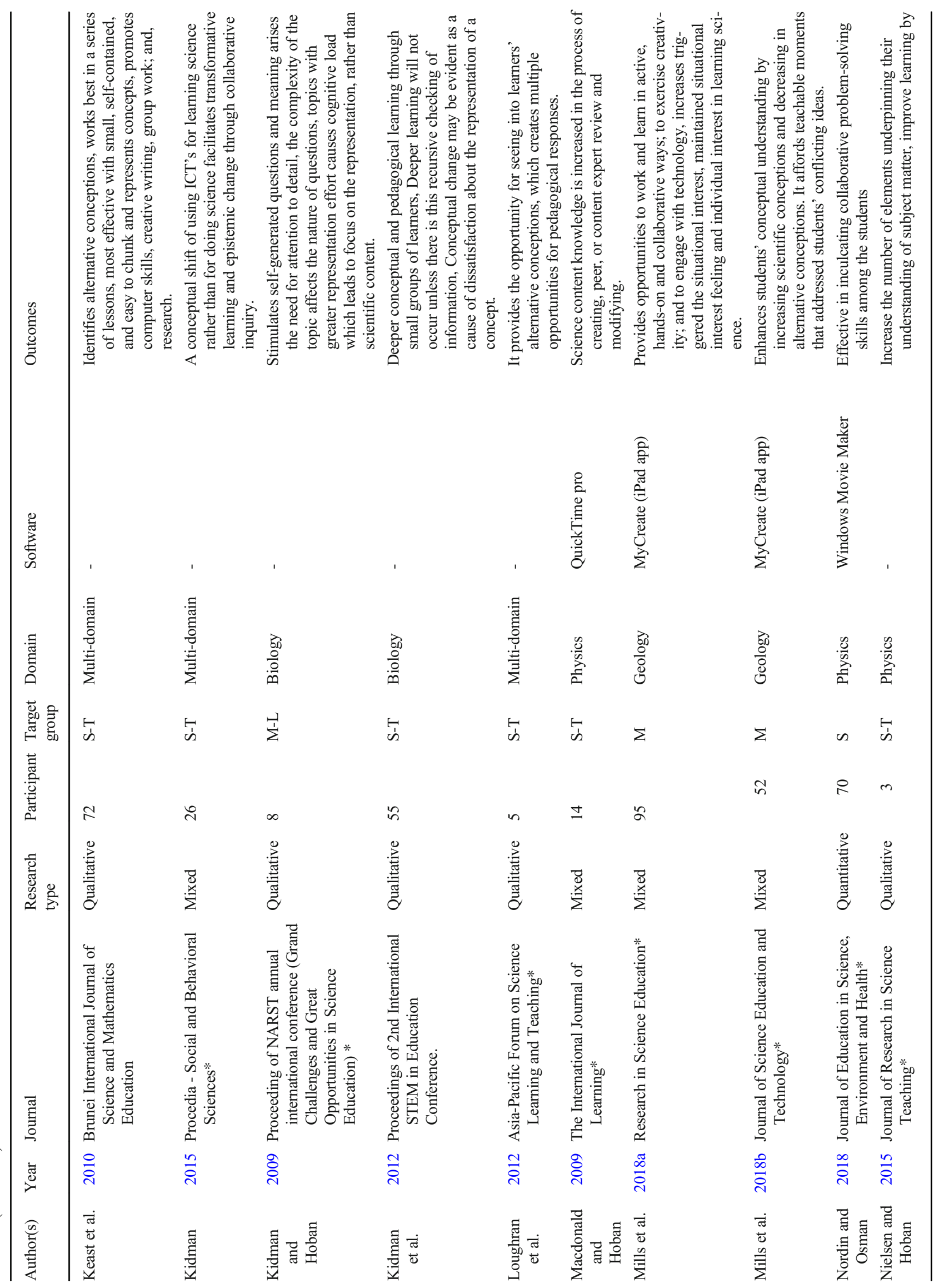




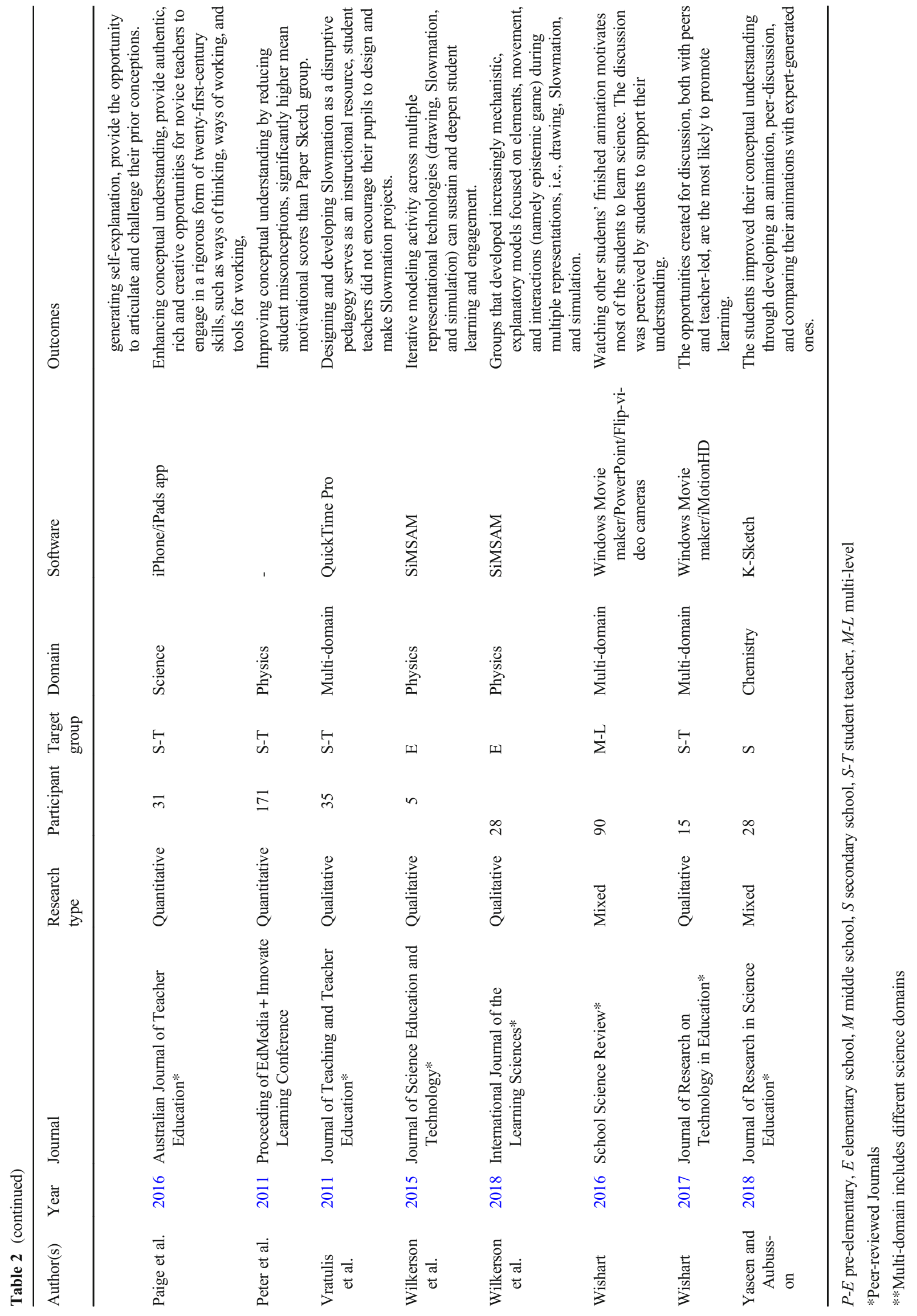


Open Access This article is licensed under a Creative Commons Attribution 4.0 International License, which permits use, sharing, adaptation, distribution and reproduction in any medium or format, as long as you give appropriate credit to the original author(s) and the source, provide a link to the Creative Commons licence, and indicate if changes were made. The images or other third party material in this article are included in the article's Creative Commons licence, unless indicated otherwise in a credit line to the material. If material is not included in the article's Creative Commons licence and your intended use is not permitted by statutory regulation or exceeds the permitted use, you will need to obtain permission directly from the copyright holder. To view a copy of this licence, visit http://creativecommons.org/licenses/by/4.0/.

\section{References}

*Akaygun, S. (2016). Is the oxygen atom static or dynamic? The effect of generating animations on students' mental models of atomic structure. Chemistry Education Research and Practice, 17(4), 788-807. https://doi.org/10.1039/C6RP00067C.

Akaygun, S., \& Jones, L. L. (2013). Research-based design and development of a simulation of liquid-vapor equilibrium. Chemistry Education Research and Practice, 14(3), 324-344. https://doi.org/ 10.1039/C3RP00002H.

*Atalay, N., \& Belet Boyaci, Ș. D. (2019). Slowmation application in development of learning and innovation skills of students in science course. International Electronic Journal of Elementary Education, 11(5), 507-518. https://iejee.com/index.php/IEJEE/article/view/824

Aubusson, P., Treagust, D. F., \& Harrison, A. G. (2009). Learning and teaching science with analogies and metaphors. In Ritchie. S. (Ed.), The world of science education: Handbook of research in Australasia vol. 2 (pp. 199-216). Sense Publishers. https://opus. lib.uts.edu.au/handle/10453/12456

*Berg, A., Orraryd, D., Pettersson, A. J., \& Hultén, M. (2019). Representational challenges in animated chemistry: Self-generated animations as a means to encourage students' reflections on submicro processes in laboratory exercises. Chemistry Education Research and Practice, 20(4), 710-737. https://doi.org/10.1039/ c8rp00288f.

Beyaztaş, D., \& Senemoğlu, N. (2015). Learning approaches of successful students and factors affecting their learning approaches. Education in Science, 40, 193-216.

Biggs, J. (2003). Teaching for quality learning at university (2nd ed.). The Society for Research into Higher Education and Open University Press.

*Bogiages, C., \& Hitt, A. M. (2008). Movie mitosis: Students make stopanimation films to illustrate the process of mitosis. The Science Teacher, 75(9), 36-43. https://doi.org/10.2307/24144165.

Brereton, P., Kitchenham, B. A., Budgen, D., Turner, M., \& Khalil, M. (2007). Lessons from applying the systematic literature review process within the software engineering domain. Journal of Systems and Software, 80(4), 571-583. https://doi.org/10.1016/J.JSS.2006. 07.009 .

*Brown, J., Murcia, K., \& Hackling, M. (2013). Slowmation: A multimodal strategy for engaging children with primary science. Teaching Science: Australian Science Teachers Journal, 59, 14-20.

*Chang, H. Y., Quintana, C., \& Krajcik, J. S. (2010). The impact of designing and evaluating molecular animations on how well middle school students understand the particulate nature of matter. Science Education, 94, 73-94. https://doi.org/10.1002/sce.20352.

ChanLin, L.-J. (2001). Formats and prior knowledge on learning in a computer-based lesson. Journal of Computer Assisted Learning, 17(4), 409-419. https://doi.org/10.1046/j.0266-4909.2001.00197.x.

Chi, M. T. H. (2009). Active-constructive-interactive: A conceptual framework for differentiating learning activities. Topics in
Cognitive Science, 1(1), 73-105. https://doi.org/10.1111/j.17568765.2008.01005.x.

*Church, W., Gravel, B., \& Rogers, C. (2007). Teaching parabolic motion with stop-action animations. International Journal of Engineering Education, 23, 861-867.

Danish, J. A., \& Enyedy, N. (2007). Negotiated representational mediators: How young children decide what to include in their science representations. Science Education, 91(1), 1-35. https://doi.org/10. 1002/sce.20166.

Davidowitz, B., Chittleborough, G., \& Murray, E. (2010). Studentgenerated submicro diagrams: A useful tool for teaching and learning chemical equations and stoichiometry. Chemical Education Research and Practice, 11(3), 154-164. https://doi.org/10.1039/ C005464J.

DiSessa, A. A., \& Sherin, B. L. (2000). Meta-representation: An introduction. The Journal of Mathematical Behavior, 19(4), 385-398. https://doi.org/10.1016/S0732-3123(01)00051-7.

Dochy, F., Segers, M., Van den Bossche, P., \& Gijbels, D. (2003). Effects of problem-based learning: A meta-analysis. Learning and Instruction, 13(5), 533-568. https://doi.org/10.1016/S09594752(02)00025-7.

*Ekici, E., \& Ekici, F. (2014). Prospective science teachers' selfassessments about the use of Slowmation approach in teaching. European Journal of Social Sciences Education and Research, 1(1), 91-94. https://doi.org/10.26417/ejser.v1i1.p91-94.

*Ekici, F., Cakmak, N., \& Ekici, E. (2014). Using Slowmation as a teaching approach and its effect on biology achievements of preservice science teachers. The Eurasia Proceedings of Educational \& Social Sciences (EPESS), 316-321.

Evagorou, M., Erduran, S., \& Mäntylä, T. (2015). The role of visual representations in scientific practices: From conceptual understanding and knowledge generation to 'seeing' how science works. International Journal of STEM Education, 2(1), 11. https://doi.org/ 10.1186/s40594-015-0024-x.

Felder, R. M., \& Brent, R. (2005). Understanding student differences. Journal of Engineering Education, 94(1), 57-72. https://doi.org/ 10.1002/j.2168-9830.2005.tb00829.x.

*Fleer, M., \& Hoban, G. (2012). Using "Slowmation" for intentional teaching in early childhood centres: Possibilities and imaginings. Australasian Journal of Early Childhood, 37(3), 61-70. http:// search.ebscohost.com/login. aspx ?direct $=$ true $\& d b=a s x \& A N=$ 82073830\&site=eds-live

Flood, J., Lapp, D., \& Heath, S. B. (2004). Handbook of research on teaching literacy through the communicative and visual arts. Lawrence Erlbaum Associates. https://doi.org/10.4324/ 9781410611161.

Gobert, J. D., \& Clement, J. J. (1999). Effects of student-generated diagrams versus student-generated summaries on conceptual understanding of causal and dynamic knowledge in plate tectonics. Journal of Research in Science Teaching, 36(1), 39-53. https:// doi.org/10.1002/(SICI)1098-2736(199901)36:1<39::AIDTEA4>3.0.CO;2-I.

Heijnes, D., van Joolingen, W., \& Leenaars, F. (2018). Stimulating scientific reasoning with drawing-based modeling. Journal of Science Education and Technology, 27(1), 45-56. https://doi.org/10.1007/ s10956-017-9707-z.

*Hoban, G. (2005). From claymation to slowmation: A teaching procedure to develop students' science understandings. Teaching. Teaching Science: Australian Science Teachers Journal, 51, 26-30.

*Hoban, G. (2007). Using Slowmation to engage preservice elementary teachers in understanding science content knowledge. Contemporary Issues in Technology and Teacher Education, 7, 75-91.

Hoban, G. (2009). Facilitating learner-generated animations with Slowmation. In L. Lockyer, S. Bennett, S. Agostinho, \& B. Harper (Eds.), Handbook of Research on Learning Design and Learning 
Objects (pp. 312-329). IGI Global. https://oi.org/10.4018/978-159904-861-1.ch015.

*Hoban, G., \& Ferry, B. (2006). Teaching science concepts in higher education classes with slow motion animation (slowmation). World Conference on E-Learning in Corporate, Government, Healthcare \& Higher Education, 1641-1646. https://ro.uow.edu. au/edupapers/595

*Hoban, G., \& Nielsen, W. (2010). The 5 Rs: A new teaching approach to encourage Slowmations (student-generated animations) of science concepts. Teaching Science, 56, 33-38. https://eric.ed.gov/?id= EJ907333

*Hoban, G., \& Nielsen, W. (2012). Using "Slowmation" to enable preservice primary teachers to create multimodal representations of science concepts. Research in Science Education, 42(6), 11011119. https://doi.org/10.1007/s11165-011-9236-3.

*Hoban, G., \& Nielsen, W. (2013). Learning science through creating a 'Slowmation': A case study of preservice primary teachers. International Journal of Science Education, 35(1), 119-146. https://doi.org/10.1080/09500693.2012.670286.

*Hoban, G., \& Nielsen, W. (2014). Creating a narrated stop-motion animation to explain science: The affordances of "Slowmation" for generating discussion. Teaching and Teacher Education, 42, 6878. https://doi.org/10.1016/J.TATE.2014.04.007.

*Hoban, G., Ferry, B., Konza, D. M., \& Vialle, W. J. (2007). Slowmation: Exploring a new teaching approach in primary school classrooms. In J. Kiggins, L. K. Kervin, \& J. Mantei (Eds.), Quality in teacher education: Considering different perspectives and agendas. Proceedings of the 2007 Australian Teacher Education Association National Conference (pp. 207-217). Australian Teacher Education Association.

*Hoban, G., Macdonald, D. C., Ferry, B., \& Hoban, S. (2009a). Simplifying animation with "Slowmation" to encourage preservice teachers' science learning and teaching. Research Online, EDMEDIA200, 2838-2847. https://doi.org/10.1186/1475-2875-11159.

*Hoban, G., Nielsen, W., Macdonald, D., \& Ferry, B. (2009b). Validating the Slowmation learning design: Comparing a learning design with students' experiences of learning. Proceedings of The Future of Learning Designs Conference, 61-68. https://ro.uow.edu.au/ edupapers $/ 1047$

*Hoban, G., Loughran, J., \& Nielsen, W. (2011). Slowmation: Preservice elementary teachers representing science knowledge through creating multimodal digital animations. Journal of Research in Science Teaching, 48, 985-1009. https://doi.org/10.1002/tea.20436, 9.

Höffler, T. N. (2010). Spatial ability: Its influence on learning with visualizations - A meta-analytic review. Educational Psychology Review, 22(3), 245-269. https://doi.org/10.1007/s10648-010-91267.

Hubber, P., Tytler, R., \& Haslam, F. (2010). Teaching and learning about force with a representational focus: Pedagogy and teacher change. Research in Science Education, 40(1), 5-28. https://doi.org/10. 1007/s11165-009-9154-9.

*Jablonski, D., Hoban, G., Ransom, H. S., \& Ward, K. S. (2015). Exploring the use of "Slowmation" as a pedagogical alternative in science teaching and learning. Pacific-Asian Education Journal, 27, 5-20.

*Kamp, B. L., \& Deaton, C. C. M. (2013). Move, stop, learn: Illustrating mitosis through stop-motion animation. Science Activities: Classroom Projects and Curriculum Ideas, 50(4), 146-153. https:// doi.org/10.1080/00368121.2013.851641.

*Karakoyun, F., \& Yapıcı, İ. Ü. (2018). Use of Slowmation in biology teaching. International Education Studies, 11(10), 16-27. https:// doi.org/10.5539/ies.v11n10p16.

*Keast, S., Cooper, R., Berry, A., Loughran, J., \& Hoban, G. (2010). Slowmation as a pedagogical scaffold for improving science teaching and learning. Brunei International Journal of Science and
Mathematics Education, 2, 1-15. http://ro.uow.edu.au/edupapers/ 1046/?utm_source=rss\&utm_medium $=$ rss\&utm_campaign $=$ slowmation-as-a-pedagogical-scaffold-for-improving-scienceteaching-and-learning

*Kidman, G. (2015). Facilitating meta-learning in pre-service teachers: Using integration and Slowmation animation. Procedia - Social and Behavioral Sciences, 167, 117-123. https://doi.org/10.1016/J. SBSPRO.2014.12.652.

*Kidman, G., \& Hoban, G. (2009). Biotechnology learnings using 'Claymation' and 'Slowmation.' 2009 NARST Grand Challenges and Great Opportunities in Science Education. https://eprints.qut. edu.au/28906/

*Kidman, G., Keast, S., \& Cooper, R. (2012). Understanding pre-service teacher conceptual change through Slowmation animation. Proceedings of 2nd International STEM in Education Conference, $1-9$.

Klein, P. D. (2003). Rethinking the multiplicity of cognitive resources and curricular representations: Alternatives to "learning styles" and "multiple intelligences." Journal of Curriculum Studies, 35(1), 4581. https://doi.org/10.1080/00220270210141891.

Kozma, R., \& Russell, J. (2005). Students becoming chemists: Developing representational competence. In J. K. Gilbert (Ed.), Visualization in Science Education (pp. 121-145). Springer. https://doi.org/10.1007/1-4020-3613-2 8.

Levin, H. M. (2012). The utility and need for incorporating non-cognitive skills into large-scale educational assessments. In M. von Davier, E. Gonzalez, I. Kirsch, \& K. Yamamoto (Eds.), The role of international large-scale assessments: Perspectives from technology, economy, and educational research (pp. 67-86). Springer. https://doi. org/10.1007/978-94-007-4629-9_5.

Linnenbrink-Garcia, L., Durik, A. M., Conley, A. M., Barron, K. E., Tauer, J. M., Karabenick, S. A., \& Harackiewicz, J. M. (2010). Measuring situational interest in academic domains. Educational and Psychological Measurement, 70(4), 647-671. https://doi.org/ 10.1177/0013164409355699.

*Loughran, J., Berry, A., Cooper, R., Keast, S., \& Hoban, G. (2012). Preservice teachers learning about teaching for conceptual change through Slowmation. Asia-Pacific Forum on Science Learning and Teaching, 13, 1-28. https://eric.ed.gov/?id=EJ990367

*Macdonald, D., \& Hoban, G. (2009). Developing science content knowledge through the creation of Slowmations. The International Journal of Learning, 16, 319-330. https://ro.uow.edu.au/edupapers/ 107

Magnusson, S., Krajcik, J., \& Borko, H. (1999). Nature, sources and development of pedagogical content knowledge for science teaching. In J. Gess-Newsome \& N. G. Lederman (Eds.), Examining pedagogical content knowledge (pp. 95-132). Kluwer Academic Publishers.

Marunic, G., \& Glazar, V. (2014). Improvement and assessment of spatial abilitiy in engineering education. Engineering Review, 34, 139-150.

Mayer, R. E. (1994). Visual aids to knowledge construction: Building mental representations from pictures and words. In Advances in psychology (Vol. 108, pp. 125-138). North-Holland. https://doi. org/10.1016/S0166-4115(09)60112-6.

*Mills, R., Tomas, L., \& Lewthwaite, B. (2018a). The impact of studentconstructed animation on middle school students' learning about plate tectonics. Journal of Science Education and Technology, 113. https://doi.org/10.1007/s10956-018-9755-z.

*Mills, R., Tomas, L., Whiteford, C., \& Lewthwaite, B. (2018b). Developing middle school students' interest in learning science and geology through Slowmation. Research in Science Education, 1-20. https://doi.org/10.1007/s11165-018-9741-8

*Nielsen, W., \& Hoban, G. (2015). Designing a digital teaching resource to explain phases of the moon: A case study of preservice elementary teachers making a Slowmation. Journal of Research in Science Teaching, 52(9), 1207-1233. https://doi.org/10.1002/tea.21242. 
*Nordin, N. M., \& Osman, K. (2018). Students' generated animation: An innovative approach to inculcate collaborative problem solving (CPS) skills in learning physics. Journal of Education in Science, Environment and Health, 4, 206-226. https://doi.org/10.21891/ jeseh.436758.

Noroozi, O., Weinberger, A., Biemans, H. J. A. A., Mulder, M., \& Chizari, M. (2012). Argumentation-based computer supported collaborative learning (ABCSCL): A synthesis of 15 years of research. Educational Research Review, 7(2), 79-106. https://doi.org/10. 1016/j.edurev.2011.11.006.

Olde, C. V., \& de Jong, T. (2004). Student-generated assignments about electrical circuits in a computer simulation. International Journal of Science Education, 26(7), 859-873. https://doi.org/10.1080/ 0950069032000138815.

Oliveira, A., Feyzi Behnagh, R., Ni, L., Mohsinah, A. A., Burgess, K. J., \& Guo, L. (2019). Emerging technologies as pedagogical tools for teaching and learning science: A literature review. Human Behavior and Emerging Technologies, 1(2), 149-160. https://doi.org/10. 1002/hbe2.141.

*Paige, K., Bentley, B., \& Dobson, S. (2016). Slowmation: An innovative twenty-first century teaching and learning tool for science and mathematics pre-service teachers. The Australian Journal of Teacher Education, 41, 1-15. https://doi.org/10.14221/ajte. 2016v41n2.1.

Peirce, C. S. (1955). Logic as semiotic: The theory of signs. In B. Justus (Ed.), Philosophical writings of Peirce, (p. 386). Dover Publications https://www.worldcat.org/title/philosophical-writings-of-peirce/ oclc/988216444.

* Peter, D. R., Chong, T. S., Abbas, M. (2011). Effectiveness of Slowmation when used as a desired difficulty construction task in the learning of moon phases, Proceedings of ED-MEDIA 2011World Conference on Educational Multimedia, Hypermedia \& Telecommunications 3690 (2011). https://www.learntechlib.org/p/ $38392 /$

Quillin, K., \& Thomas, S. (2015). Drawing-to-learn: A framework for using drawings to promote model-based reasoning in biology. $C B E$ Life Sciences Education, 14, es2. https://doi.org/10.1187/cbe.14-080128.

Shi, Y., Ma, Y., MacLeod, J., \& Yang, H. H. (2020). College students' cognitive learning outcomes in flipped classroom instruction: A meta-analysis of the empirical literature. Journal of Computers in Education, 7(1), 79-103. https://doi.org/10.1007/s40692-01900142-8.

Stieff, M., Bateman, R. C., \& Uttal, D. H. (2005). Teaching and learning with three-dimensional representations. In J. K. Gilbert (Ed.), Visualization in Science Education (pp. 93-120). Springer. https:// doi.org/10.1007/1-4020-3613-2_7.

Sudatha, I. G. W., Degeng, I. N. S., \& Kamdi, W. (2018). The effect of visualization type and student spatial abilities on learning achievement. Journal of Baltic Science Education, 17(4), 551-563.

Theelen, H., van den Beemt, A., \& den Brok, P. (2019). Classroom simulations in teacher education to support preservice teachers' interpersonal competence: A systematic literature review. Computers in Education, 129, 14-26. https://doi.org/10.1016/J.COMPEDU. 2018.10.015.
Van Dinther, M., Dochy, F., \& Segers, M. (2011). Factors affecting students' self-efficacy in higher education. Educational Research Review, 6(2), 95-108. https://doi.org/10.1016/J.EDUREV.2010. 10.003 .

*Vratulis, V., Clarke, T., Hoban, G., \& Erickson, G. (2011). Additive and disruptive pedagogies: The use of Slowmation as an example of digital technology implementation. Teaching and Teacher Education, 27(8), 1179-1188. https://doi.org/10.1016/j.tate.2011. 06.004 .

Walker, P. (2008). What do students think they (should) learn at college? Student perceptions of essential learning outcomes. Journal of the Scholarship of Teaching and Learning, 8(1), 45-60.

Wanzer, D., Postlewaite, E., \& Zargarpour, N. (2019). Relationships among non-cognitive factors and academic performance: Testing the University of Chicago Consortium on school research model. AERA Open, 5(4), 1-20. https://doi.org/10.1177/ 2332858419897275.

*Wilkerson, M. H., Gravel, B. E., \& Macrander, C. A. (2015). Exploring shifts in middle school learners' modeling activity while generating drawings, animations, and computational simulations of molecular diffusion. Journal of Science Education and Technology, 24(2-3), 396-415. https://doi.org/10.1007/s10956-014-9497-5.

*Wilkerson, M. H., Shareff, R., Laina, V., \& Gravel, B. (2018). Epistemic gameplay and discovery in computational model-based inquiry activities. Instructional Science, 46(1), 35-60. https://doi.org/10.1007/ s11251-017-9430-4.

*Wishart, J. (2016). Learning science through creating simple animations in both primary and secondary schools. School Science Review, 97, $117-124$.

*Wishart, J. (2017). Exploring how creating stop-motion animations supports student teachers in learning to teach science. Journal of Research on Technology in Education, 49(1-2), 88-101. https:// doi.org/10.1080/15391523.2017.1291316.

Wu, H.-K., \& Puntambekar, S. (2012). Pedagogical affordances of multiple external representations in scientific processes. Journal of Science Education and Technology, 21(6), 754-767. https://doi. org/10.1007/s10956-011-9363-7.

*Yaseen, Z., \& Aubusson, P. (2018). Exploring student-generated animations, combined with a representational pedagogy, as a tool for learning in chemistry. Research in Science Education, 1-20. https:// doi.org/10.1007/s11165-018-9700-4.

Yore, L. D., \& Treagust, D. F. (2006). Current realities and future possibilities: Language and science literacy-Empowering research and informing instruction. International Journal of Science Education, 28(2-3), 291-314. https://doi.org/10.1080/09500690500336973.

Zhang, Z. H., \& Linn, M. C. (2011). Can generating representations enhance learning with dynamic visualizations? Journal of Research in Science Teaching, 48(10), 1177-1198. https://doi.org/ 10.1002/tea.20443.

Publisher's Note Springer Nature remains neutral with regard to jurisdictional claims in published maps and institutional affiliations. 